\title{
Investigating the Effects of Coarse Aggregate Physical Properties on Strength of C-25 Concrete
}

\author{
Getnet Tadesse Abegaz ${ }^{1}$, Imran Khan ${ }^{1}$, Alemu Mosisa Legese ${ }^{2}$ \\ ${ }^{1}$ Department of Construction Technology and Management, College of Engineering and Technology, Wollega University, Nekemte, Ethiopia \\ ${ }^{2}$ Department of Civil Engineering, Institute of Technology, Jimma University, Jimma, Ethiopia
}

Email address:

getnetadesse@gamil.com (G. T. Abegaz), ashok4094@gmail.com (I. Khan), amosisa@gmail.com (A. M. Legese)

\section{To cite this article:}

Getnet Tadesse Abegaz, Imran Khan, Alemu Mosisa Legese. Investigating the Effects of Coarse Aggregate Physical Properties on Strength of C-25 Concrete. American Journal of Engineering and Technology Management. Vol. 5, No. 5, 2020, pp. 84-90.

doi: 10.11648/j.ajetm.20200505.12

Received: October 22, 2020; Accepted: November 10, 2020; Published: November 23, 2020

\begin{abstract}
The strength of concrete mostly depends on the strength and properties of coarse aggregate since the major volume of concrete was covered by coarse aggregate. The physical properties of coarse aggregates do grossly affect the workability and structural performance of concrete. This study considered the effects of physical properties of coarse aggregate on properties of concrete and the difference in strength of concrete made from four different types of coarse aggregates namely crushed basalt, crushed marble, river graver and surface gravel which were collected from different areas near to Nekemte town. For each types of collected coarse aggregate their physical properties are determined by performing necessary laboratory tests to attain the objective of the study. For proportioning of concrete making materials the ACI concrete mix design was followed. Total of 36 cubes and 12 beam molds were casted for determination of compressive strength flexural strength of C25 concrete made from the four aggregate samples. The results indicate physical properties and types of coarse aggregate have effects on the strength of concrete. The four coarse aggregate samples have different physical properties and produced concrete having different compressive and flexural strength. Thus, it concludes, the compressive and flexural strength of concrete was greatly influenced by the physical properties and strength of coarse aggregate.
\end{abstract}

Keywords: Concrete Compressive Strength, Flexural Strengths, Physical Properties of Coarse Aggregate, Types of Coarse Aggregate, etc

\section{Introduction}

Concrete is a heterogeneous material and strength by cement paste is not fully retained when sand and aggregate are added. The strength of concrete is one of the most important properties of concrete. The concrete making properties of various ingredients of mix are usually measured in terms of the compressive strength. Aggregates added in concrete are the important constituents in concrete. Aggregates are chemically active and also that certain aggregates exhibit chemical bond at the interface of aggregate and paste. [6].

Although aggregates are most commonly known to be inert filler in concrete, the different properties of aggregate have a large impact on the strength, durability, workability, and economy of concrete. These different properties of aggregate allow designers and contractors the most flexibility to meet their design and construction requirements [17].

The physical properties like specific gravity, porosity, thermal, and the chemical properties of an aggregate are attributed to the parent rock. However, the shape and surface texture of natural aggregates and the density, porosity, in addition to shape and surface texture in artificial aggregates are attributed from the mode of production. It is, therefore, very important to give a due consideration to the source and mode of production of aggregates. Aggregate properties significantly affect the workability of plastic concrete and the durability, strength, thermal properties, and density of hardened concrete [10].

Since up to approximately $80 \%$ of the total volume of concrete consists of aggregate, aggregate characteristics significantly affect the performance of fresh and hardened concrete and have an impact on the cost of concrete [9]. Thus, in this study, the relative effect of the variations in the physical 
properties and types of coarse aggregates on the compressive and flexural strength of the concretes was investigated.

\section{Review of Related Literatures}

Concrete needs to be designed for certain properties in the plastic stage as well as in the hardened stage. Aggregates amount to at least three-quarter of the volume of normal weight of concrete and they are cheaper than cement and also confer a considerable better durability in concrete than the ordinary cement paste [3].

Strength performance remains the most important property of structural concrete, from an engineering viewpoint. The strength of the concrete is determined by the characteristics of the mortar, coarse aggregate, and the interface. For the same quality mortar, different types of coarse aggregate with different shape, texture, mineralogy, and strength may result in different concrete strengths. However, the limitation of the water/cement ratio (W/C) concept is becoming more apparent with the development of high-performance concrete, in which the aggregate plays a more important role [1].

It is assumed that the type of aggregate does not affect the properties of concrete. If aggregates are dense and strong, the properties of concrete are governed by the quality of the paste, and shape, surface texture, maximum size, and grading of the aggregates. However, in case of average- and lowquality aggregates, usually characterized as porous and weak, the properties of concrete are found to be significantly affected by the types of aggregates. The mechanical properties of high-performance concrete, have found that the strength, stiffness, and fracture energy of concrete for a given water/cement ratio depend on the type of aggregate, especially for high-strength concrete. They suggested that for producing high-strength concrete with low brittleness, highstrength aggregate with low brittleness should be used [6].

Abdullahi M. in his study states Aggregate type has effect on the compressive strength of normal concrete. Highest compressive strength was achieved from concrete containing crushed quartzite, followed by concrete containing river gravel. Concrete containing crushed granite shows the least strength development at all ages [11], The study by Ke-Ru $\mathrm{Wu}$ et al shows, Concrete mixes made with crushed limestone give higher strength and elasticity than concrete mixes made with crushed gravel, and concrete mixes made with crushed gravel gave higher strength and elasticity than concrete mixes made with uncrushed gravel [9]. Aginam, C. $\mathrm{H}$, et, al, compared the compressive strength of concrete made from gravels (washed and unwashed) with crushed granite and the results indicates there was increase in strength at growing curing ages and in all instances, the compressive strength of the unwashed gravel is the minimum. And also recommend that Gravels will require more water to be workable hence could be adduced for reduced compressive strength. [14].

Hassan NS (2014) studied the effects of the type of coarse aggregates on the flexural and compressive strength of concrete, and states at all curing ages, flexural strengths for basalt mixes were higher than limestone mixes with the same mix proportions. The compressive strength for basalt mixes was also higher than limestone mixes [12].

Z. Wadud, et al (2001), generalized that with the increase of void ratio in the coarse aggregates, the proportion of the fine aggregate increases in comparison to the coarse aggregate. This increase in the fine aggregate greatly increases the total surface area of the aggregates; this increase in total surface area would have required a larger amount of cement.

The Void contents between aggregate particles increases with increasing in aggregate angularity. Void contents range from $30 \%$ to $45 \%$ for coarse aggregate. Total volume of voids can be reduced by using a collection of aggregate sizes [15].

Moisture content in concrete does have a significant effect on the compressive strength of concrete, but have a much lesser effect on the split tensile strength. As the specimen degrees of saturation increased, the compressive strength fell. However, at nearly saturated condition, an increase in compressive strength can be found [16].

M. Nishat (2016), studied the relation between strength coarse aggregate and compressive strength of concrete and, states that the stronger and cleaner the aggregates, the better the strength performance of concrete [8].

M. Shetty states the shape and surface texture of coarse aggregate affects the properties of fresh concrete more than hardened concrete and concrete is more workable when smooth and rounded aggregate is used instead of rough angular or elongated aggregate [6].

The effect of the coarse aggregate type on compressive strength investigated by Druta, show that crushed limestone in the mixes gave higher compressive and flexural strengths and modulus of elasticity than crushed gravel in the mixes. This behavior is attributed to the effect of chemical interaction and the rougher surface texture of particles, where the bond between aggregate and paste is stronger. In addition, the results indicate that mixes that have crushed gravel give (compressive and flexural) strength and modulus of elasticity values higher than uncrushed gravel. This may be attributed to the roughness of the surface of crushed gravel as compared with the surface of uncrushed gravel [13].

\section{Materials and Methods}

The study adopts purposive sampling method. The crushed basalt was purchased from an aggregate production of HIR quarry at Sorga near Nekemte Referral hospital, and crushed marble delivered from diga aggregate crushing quarry. River Gravel and surface gravel were collected from Bolo River and bolo area respectively which is $5 \mathrm{Km}$ from Nekemte town and River sand was purchased from an aggregates merchant on Hangar River. Commercially available Dangote Ordinary Portland Cement (OPC) and Potable drinking water were used for this research work.

For this study physical properties of coarse aggregate were performed according to ASTM standards for each coarse aggregate type and also Aggregate impact tests were in a 
surface dry condition of aggregate and conducted in accordance with BS 812-112.

For materials proportioning of each coarse aggregate sample ACI concrete mix design is followed. For each tests weighting was used for sampling technique.

After determining the amount of ingredients and water required for each aggregate type Materials were mixed by mechanical mixer. The molds were cleaned off dust and oil was applied on all sides of molds before concreting the sample. Thoroughly mixed concrete was poured into $150 \mathrm{~mm} \times 150 \mathrm{~mm} \times 150 \mathrm{~mm}$ cubes in three equal layers and compacted manually by using rod 25 times for each layer. Excess concrete is removed with a trowel and the top surface was finished with a smooth surface. Total of 36 cubes were casted for determination of Compressive strength and the identification codes and numbers are given for each sample. After 24 hour the samples were de-molded and put in curing tanker for the respective periods of 7 day, 14 day and 28 day. For each aggregate type 3 samples at each curing days were removed from curing tank to test compressive strength and the cubes were weighed and crushed using Denison crushing machine. The ratio of the crushing loads to the surface area of the cubes gave the compressive strengths of concrete.

Flexural test was performed using two-point loading, in accordance with ASTM C78, using hydraulic testing machine, and to achieve the flexural strength of the concrete nine beam molds with $500 \mathrm{~mm} \times 100 \mathrm{~mm} \times 100 \mathrm{~mm}$ for flexural strength were prepared only for 28 days. The test specimens was prepared by filling the concrete into the mold in 3 layers of approximately equal thickness and tamping each layer 35 times using the tamping bar. After 24 hours the beams were stored in water tank for 28 days. After 28 curing days, the beams were removed from the curing tank and the flexural load is applied on the each samples. and the result of flexural strength was calculated by the flexural strength machine.

\section{Result and Discussion}

\subsection{Gradation of Coarse and Fine Aggregate}

The sieve analysis carried out on both the fine and coarse aggregates in accordance with the guidelines specified by ASTM C136. The result of particle size distribution indicates that the fine and coarse aggregate maximum sizes used for the study were greater than $4.75 \mathrm{~mm}$ and $37.5 \mathrm{~mm}$ respectively. This shows the Nominal maximum size of coarse aggregate was $37.5 \mathrm{~mm}$.

In this experimental work the fine modulus of fine aggregate was 2.8 and that of coarse aggregates (crushed basalt, river gravel and surface gravel and crushed marble) were $7.45,7.48,7.52$ and 7.5 respectively.

The result indicates the washed gravel was coarser than the other aggregate samples and followed by crushed marble, river gravel and crushed basalt.

\subsection{Specific Gravity and Water Absorption of Coarse Aggregate}

The relative Density or Specific Gravity of the aggregates performed in the investigation in accordance with the specifications of ASTM $(\mathrm{C} 127$ and C128, 2012) [5].

Table 1. The average specific gravity and Absorption capacity of coarse aggregate sample.

\begin{tabular}{lllll}
\hline Types & Crushed Basalt & River Gravel & Crushed Marble & Washed Gravel \\
\hline Sample taken in g & 1000 & 1000 & 1000 & 1000 \\
Weight of SSD & 1010.5 & 1007.7 & 1012.56 & 1020.2 \\
Wet weight & 634.7 & 641.6 & 618.4 & 614.1 \\
Oven dry Weight & 982.2 & 992 & 986.25 & 975.5 \\
Apparent Sp. gravity & 2.81 & 2.84 & 2.68 & 2.69 \\
Bulk Sp. Gravity BULK SSD & 2.68 & 2.75 & 2.58 & 2.54 \\
Bulk SG & 2.61 & 2.71 & 2.52 & 2.48 \\
Absorption & 2.67 & 1.58 & 2.36 & 2.8 \\
Total MC & 1.60 & 0.80 & 1.39 & 2.61 \\
\hline
\end{tabular}

Most normal mass aggregates have a bulk specific gravity SSD between 2.4 and 2.9 [10], in this research work the values obtained indicate that SSD specific gravity aggregate of all aggregates fall within the standard range and that of surface gravel was at the lower limit or less than the other aggregate samples. This is because the percentage porosity of surface gravel was greater than the other coarse aggregate samples, which makes aggregate more absorptive and greater SSD weight. The crushed marble has also less specific gravity than crushed basalt and river gravel. The result specific gravities for river gravel was greater than the other, which indicates porosity in river gravel was minimum and its SSD weight was less than the other aggregate samples. This supports that, the porosity and the weight of the gravel account for its high specific gravity [14].

\subsection{Water Absorption of Coarse Aggregates}

The water absorption values of the aggregates samples were $2.67 \%, 1.58 \%, 2.86 \%, 4.58 \%$ and $3.06 \%$ for crushed aggregate, river gravel, marble, surface gravel and river sand respectively. Surface gravel has more percentage of water absorption than the other samples of aggregates. This was as a result of the fact that surface gravel contains more pores than the other aggregates, and the crushed aggregates contains more pores than that of river gravel, which is necessary for water absorption. The surface gravel did not satisfy the minimum requirement as per ASTM which is up to $3 \%$. Water interred in to internal part of the aggregate through the pores, so the aggregate with large pores absorbs more water, which highly influence the workability and strength of concrete. 


\subsection{Total Moisture Content}

All aggregates contain some moisture based on the porosity of the particles and the moisture condition of the storage area up to $2 \%$ [10]. The total moisture content of the coarse aggregate values were $1.61 \%, 1.39 \%, 0.80 \%$, and $2.51 \%, 2.04 \%$ for crushed basalt, crushed marble, river gravel, surface gravel and river sand respectively.

The surface moisture of aggregate samples used in this study were $1.06 \%$ for crushed basalt, $0.78 \%$ for river gravel, $0.97 \%$ for marble, $2.07 \%$ for washed gravel, and $1.02 \%$ for sand. The values indicate that the surface moisture of washed surface gravel was greater than the value stipulated by ASTM standard.

\subsection{Porosity of Coarse Aggregates}

The porosity of the coarse aggregate samples are $2.8 \%$, $1.56 \%$ and $4.40 \%, 2.6 \%$ for crushed basalt, river gravel, washed surface gravel and crushed marble respectively. The range of porosity of common rocks varies from 0 to 50 percent [4]. Thus, the surface gravel used in this study contains porosity greater than the other and the concrete made from coarse aggregate with more percentage of void required more paste to attain the concrete strength.

\subsection{Bulk Density or Unit Weight of Coarse Aggregates}

The unit weight of aggregate was weight of the aggregate required to fill a container of a specified unit volume. Volume is occupied by both the aggregates and voids between the aggregate particles. The higher the bulk density, the lower is the void content to be filled by sand and cement and also higher specific gravity of the particles results in higher bulk density for a particular grading The Dry-rodded bulk density of coarse aggregate 1280 to $1920 \mathrm{~kg} / \mathrm{m}^{3}$ as [10].

Thus all type of coarse aggregates used in this study were within this range, while washed surface gravel and marble aggregate falls to the minimum value.

The higher the bulk density, the lower is the void content to be filled by sand and cement, thus results obtained from this investigation showed that washed gravel and marble aggregate were less densely packed, and more void was formed between this two aggregate particles.

Table 2. The average unit weight of coarse aggregate samples.

\begin{tabular}{lll}
\hline Coarse aggregate & $\begin{array}{l}\text { Average loose unit } \\
\text { weight of coarse } \\
\text { aggregate }\end{array}$ & $\begin{array}{l}\text { Average compacted } \\
\text { unit weight of coarse } \\
\text { aggregate }\end{array}$ \\
\hline Crushed basalt & 1450.57 & 627.81 \\
River gravel & 1484.35 & 1664.31 \\
Washed gravel & 1228.39 & 1363.21 \\
Crushed marble & 1239.33 & 1384.69 \\
\hline
\end{tabular}

Therefore higher voids between coarse aggregate can reduce the bond between aggregate particles or requires more cement and sand to make bond between aggregate and cement paste which also have effect on the compressive strength of concrete.

\subsection{Void Ratio of Coarse Aggregates}

A void in unit volume of aggregate is the space between particles in an aggregate mass not occupied by solid mineral matter.

Void contents range from $30 \%$ to $45 \%$ for coarse aggregate and total volume of voids can be reduced by using a collection of aggregate sizes [7].

Voids contents affects mortar requirement in mix design; water and mortar requirement tend to increase as aggregate void content increases.

Table 3. Void ratio of coarse aggregate samples.

\begin{tabular}{lllll}
\hline Sample & $\begin{array}{l}\text { Bulk } \\
\text { density }\end{array}$ & $\begin{array}{l}\text { Bulk specific } \\
\text { gravity dry basis }\end{array}$ & $\begin{array}{l}\text { Density } \\
\text { of water }\end{array}$ & $\begin{array}{l}\text { Void } \\
\text { ratio }\end{array}$ \\
\hline $\begin{array}{l}\text { Crushed coarse } \\
\text { aggregate }\end{array}$ & 1627.78 & 2.62 & 998 & 37.74 \\
River gravel & 1664.94 & 2.71 & 988 & 37.81 \\
$\begin{array}{l}\text { Crushed Marble } \\
\text { Surface gravel }\end{array}$ & 1384.69 & 2.46 & 998 & 43.59 \\
\hline
\end{tabular}

The results of the void ratio showed that for this study the void between aggregates was more in crushed marble and surface gravel. This was due to the reason that the crushed marble and surface gravel has light in weight than the river gravel and crushed basalt which can reduce their packing ability which in turn can affect the properties of concrete.

\subsection{Shape and Surface Texture of Coarse Aggregate}

The shape and texture of aggregate affects the properties of fresh concrete more than hardened concrete. For this study the collected river gravel also has smooth in texture and rounded in shape so it expected the river gravel produce more workable concrete and surface gravel has irregular or partly rounded aggregates shaped by attrition having rounded edges, and require more cement paste and water as compared to rounded aggregate to produce workable concrete. The shape and surface texture of the crushed basalt used in this study were angular and rough respectively, and also the shape and texture of crushed marble was angular and its texture was partly rough and partly smooth. In this investigation based the compressive and flexural strength concrete made from different types of coarse aggregate, the shape and surface texture highly affects the flexural strength and workability of concrete, and also it gas lesser effect on the compressive strength.

\subsection{Aggregate Impact Value (AIV) of Coarse Aggregates}

Aggregate impact value gives a relative measure of the resistance of an aggregate sample to eternal impact Generally this test was made on single sized aggregate passing $12.5 \mathrm{~mm}$ and retained on $9.5 \mathrm{~mm}$ sieve, as per BS 812-112. 
Table 4. The impact values of the four types of aggregate.

\begin{tabular}{llllll}
\hline Weight of cone & $\begin{array}{l}\text { Average Wt of sample retained on sieve size } \\
\mathbf{9 . 5 m m}+\text { cone }\end{array}$ & $\begin{array}{l}\text { Av. Wt } \\
\text { sample taken }\end{array}$ & $\begin{array}{l}\text { Av. Wt sample passing } \\
\text { sieve size 2.36mm }\end{array}$ & $\begin{array}{l}\text { Impact } \\
\text { value }\end{array}$ & Remark \\
\hline 965.5 & 1299.1 & 333.6 & 66.4 & 19.90 & Washed Gravel \\
969.5 & 1301.1 & 331.6 & 54.1 & 16.31 & River Gravel \\
969.5 & 1309.5 & 340 & 48.4 & 14.24 & Crushed Basalt \\
969.5 & 1306.2 & 336.4 & 57.22 & 17.01 & Crushed Marble \\
\hline
\end{tabular}

These values lie in the range of BS where strong aggregates possess AIV between 10 and $20 \%$ [18]. Thus, the higher the Impact value was the lower the strength of aggregate, and the concrete form strong coarse aggregate can resist more compressive load than concrete from the weakest coarse aggregate. The washed gravel was the weakest of the four samples with the impact values of an average of $19.90 \%$, approximately $20 \%$ and produced concrete with less compressive strength. This could be due to the fact that the process of reaction with soil has softened the surface gravel.

\subsection{Concrete Fresh and Hardened Property Tests}

For determining the workability of the concrete slump test is performed from fresh properties of concrete and the Compressive and flexural tests were conducted in order to compare the desired hardened properties of concrete produced from the different types of coarse aggregate having different physical properties.

\subsubsection{Slump Test}

For slump test, sample of freshly mixed concrete was placed and compacted by rodding in a mold shaped as the frustum of a cone.

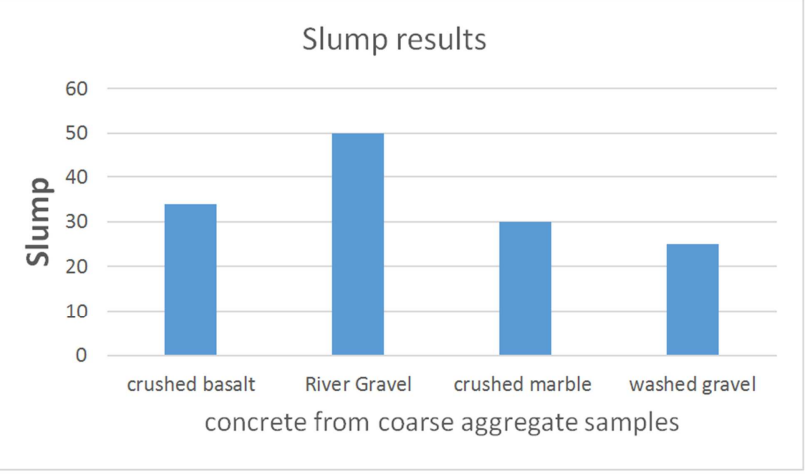

Figure 1. Slump tests of concrete for all aggregate samples.

The above result could be adduced to the fact that the surface gravel contains more pores than the other aggregate types, hence the increased porosity in aggregate particles make the concrete to requires higher water demand and cement paste to make workable concrete. The river gravel with smooth surface and rounded shape was produced the more workable concrete than coarse aggregate having angular to rough and partly rounded and irregular shape and texture respectively. This indicates that the shape and texture of aggregate affects the workability of concrete.

The river gravel also has less water absorption with less porosity and percentage voids between aggregate particles than the other thus the decreased percentage of voids lowers the amount of cement paste required for that particular mixture. Which prove the finding by Neville, A. M. (2011).

\subsubsection{Compression Test}

After preparing the mix proportions of the concrete ingredients for C-25 concrete the following compressive strength results for each maturity ages were obtained. Figure below shows that the results of compressive strength of concrete from the coarse aggregate samples, at 7, 14 and 28 days.

\section{Compressive strength results}

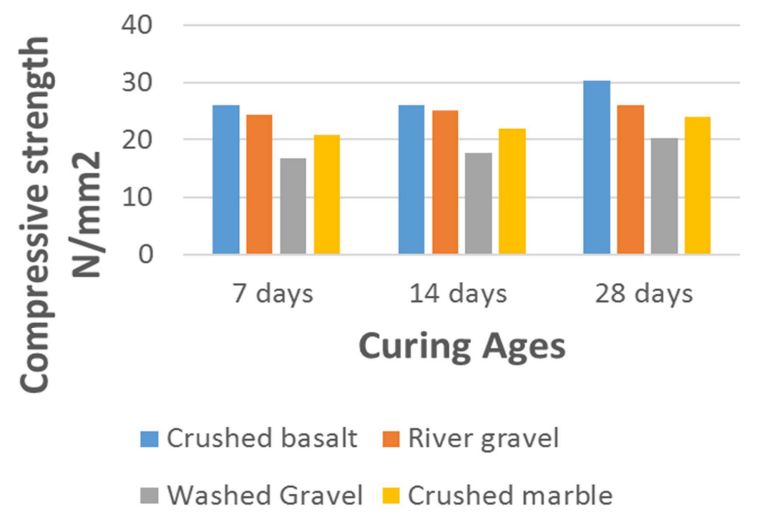

Figure 2. Cube Compressive strength of concrete from the aggregate samples.

From the result, the compressive strengths of the concrete cubes casted with all types of coarse aggregates were exceeding $65 \%$ of strength after seven days of curing age. It indicates that for M-25 all cubical specimens of concrete tested achieved their compressive strength required for 7 day curing age.

For 14 day curing age the washed surface gravel and marble were attained the minimum and less than the expected compressive strength which it was $87.44 \%$, and $71.78 \%$, while the crushed basalt and river gravel was achieved compressive strength of greater than the target mean strength at 14 days, which were $107.2 \%$ for crushed basalt and $100.68 \%$ for river gravel.

The tested at 28 days of curing age the concrete with crushed basalt was achieved the maximum compressive strength other it attained $129.72 \%$. The concrete from river gravel attained the 28 day compressive strength $104.8 \%$, whereas, the washed gravel and marble were failed to attain the required minimum compressive strength at 28 days and which $81.16 \%$ were for washed gravel and $96.06 \%$ for crushed marble.

The concrete made from crushed basalt and river gravel 
were attained more than the minimum compressive strength at all curing ages(7day, 14day and 28day), but the compressive strength of crushed basalt aggregate was greater than that of river gravel. The concrete from crushed marble and washed surface gravel was failed to achieve the required strength at 14 days and 28 days curing ages.

\subsubsection{Flexural Test}

Flexural strength is one measure of the tensile strength of concrete. It is a measure of an unreinforced concrete beam or slab to resist failure in bending. It is measured by loading $6 \mathrm{x}$ 6 inch $(100 \times 100-\mathrm{mm})$ concrete beams with a span length at least three times the depth. The flexural strength is expressed as Modulus of Rupture (MR) in $\mathrm{MPa}$ and is determined by standard test methods ASTM C 78 (third-point loading).

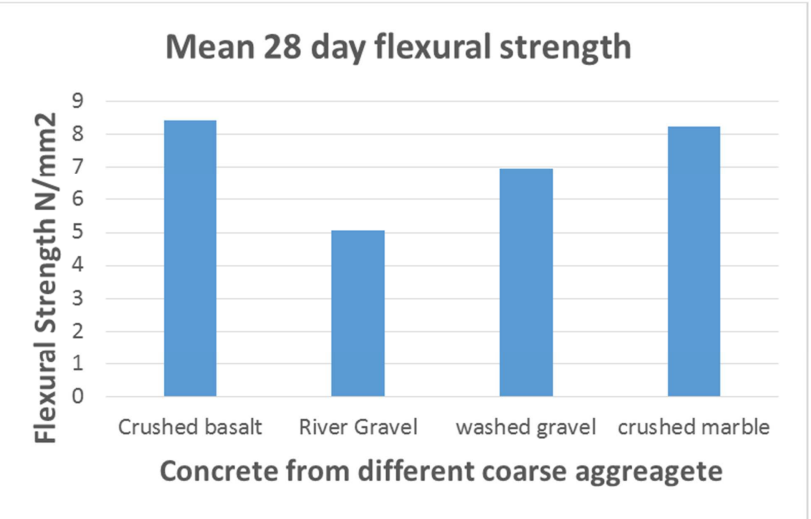

Figure 3. Flexural strength result of concrete from each aggregate sample.

The flexural strength of the selected natural coarse aggregate was tested after 28 days of curing. The flexure strength attained by concrete from crushed basalt attained the maximum strength than the other and followed by the crushed marble, washed surface and river gravel. The results of the flexural strength as shown in figure above, the concrete with river gravel attained the minimum flexural strength, but it attained the required flexural strength. The river gravel was smooth and rounded which formed less bond between aggregate particles and aggregate and paste than the other aggregate type. Thus the flexural strength of concrete was more affected by the bond between aggregate particles and paste than other physical properties of coarse aggregate.

\section{Conclusion and Recommendation}

\subsection{Conclusions}

In this study the coarse aggregate with higher Fineness modulus indicates, the coarser the aggregate become and when the particles are of uniform size the spacing is the greatest, but when a range of sizes is used the void spaces are filled and the paste requirement is lowered to make the required concrete strength.

The coarse aggregate with greater specific gravity has greater unit weight and less percentage of voids between aggregate particles and less volume of porosity, since the coarse aggregate void ratio was determined from its unit weight, its specific gravity and density of water. Thus, the large voids between aggregate particles can reduce workability and strength of concrete for the same amount of cement, and also the coarse aggregate with greater specific gravity and unit weight has less volume of porosity which can reduce the rate of strength development in concrete and requires cement paste to produce the required compressive strength of concrete. This related with Aginam, C. $\mathrm{H}$ et al, [14].

From the findings of this study the coarse aggregate with greater absorption capacity has greater moisture content and produced lesser compressive strength. Thus based on the results given above the moisture content in coarse aggregate does have a significant effect on the compressive strength of concrete, but have a much lesser effect on the flexural strength. This proves the findings of Xudong chen et al [16].

The more voids ratio in surface gravels and crushed basalt makes the concrete from such aggregates required more paste to attain the desired properties, and it reduce the bondage between aggregate particles, which highly affects the strength of concrete.

The shape and surface texture of river gravel used were rounded and smooth, which generates weak bond between aggregate particles and cement paste, however as indicated above, the river gravel was produced the concrete with required compressive strength. So it was difficult to generalize the effects of shape and surface texture on the Compressive strength of concrete, the shape and surface texture can affect the flexural strength than compressive strength.

In this study, compressive strength and AIV of the coarse aggregate samples have been determined. The results indicates that the increase in value of AIV decreases the compressive strength of concrete or the coarse aggregate having greater aggregate impact value will produced the concrete having less compressive strength, which related with the findings by M. Nishat, et al.

Crushed basalt stone aggregate provided the highest compressive and flexural strength at all curing ages, this is due to the fact that crushed basalt stone is very strong, tough and has good surface texture which enhances proper bonding between the aggregate particles and cement paste and also it was well satisfied all the required physical properties as per followed standards.

River gravel with good physical properties but having rounded shape and smooth surface texture and also good in toughness, provided higher compressive strength than crushed marble stone and washed gravel for all curing ages. But the 28 day flexural strength of concrete from river gravel was less than the concrete from the other three types of coarse aggregates.

The crushed marble with the above physical properties produced a concrete with compressive strength less target mean strength for 14 and 28 curing days. Crushed marble coarse aggregate produced a concrete having greater flexural strength than river and washed surface gravel. The washed surface gravel coarse aggregates was produced a concrete having compressive strength less than all the other and also which was less than target mean strength, but it was produced 
greater flexural strength than concrete of river gravel.

Generally, coarse aggregate physical properties have great effects on the properties of concrete especially on the workability and compressive strength of concrete and lesser effects on the flexural strength. The flexural strength was highly influenced by the bond between aggregate surface and paste.

\subsection{Recommendations}

The different properties of aggregate have significant impacts on the strength and workability concrete. These different properties of aggregate allow designers and contractors the most flexibility to meet their design and construction requirements.

The coarse aggregate having higher fineness modulus creates more voids s during mixing and required more paste to make good bond between aggregate particle and to attain the mean concrete strength

The coarse aggregate with greater specific gravity has greater unit weight and it was produced the concrete with compressive strength greater than the target mean strength at all curing ages and this type of coarse aggregate was used for normal structural concrete.

A concrete from a coarse aggregate with large void ratio required more cement paste to attain the strength and workability of concrete and pores in aggregate particles can reduce the compressive strength than flexural strength for the same amount of cement used as a binder, and also the porosity of coarse aggregate highly affects the workability of concrete, since water interred in to coarse aggregate particles through the pores.

Moisture content in coarse aggregate does have a significant effect on the compressive strength of concrete, but have a much lesser effect on the tensile strength. As the specimen degrees of saturation increased, the compressive strength fell.

The increase in Aggregate Impact value coarse aggregate was decreases the compressive strength of concrete or the coarse aggregate with greater Impact value has less compressive strength.

The shape and surface texture of coarse aggregate has less effect on compressive strength, but it was highly affected the flexural strength and workability of concrete. Thus flexural strength was highly influenced by the bond between aggregate surface and cement paste.

According to this experimental investigations result showed that, The concrete from crushed basalt and river gravel can be used for normal structural concrete works to withstand the required compressive and flexural strength. The crushed marble coarse aggregate was recommended for production of normal concrete with less water to cement ratio. The washed gravel cannot used for normal concrete production since it produced the concrete with very less than the expected compressive strength, as the main role of concrete is to withstand the compressive strength.

\section{References}

[1] Pedro Nel Quiroga and David W. Fowler the Effects of Aggregates Characteristics on the Performance of Portland cement Concrete, August 2004.

[2] Sidney M., Francis Y. J. and Darwin, D., Concrete, Second Edition, Prentice Hall, USA, 2003.

[3] Neville, A. M. (2011), Properties of Concrete, 5th Edition, Pearson Education, Delhi.

[4] EDITION A, United States Army Engineer School Fort Leonard Wood, MO 65473.

[5] American Society for Testing and Materials (ASTM), (2004), Significance of Tests and Properties of Concrete and Concrete-Making Materials.

[6] M. S Shetty, Concrete Technology, Theory and Practice, 2009, S. Chand \& Company LTD, New Delhi.

[7] Yahya Ghasemi 2017 Aggregates in Concrete Mix Design, Luleå University of Technology, Sweden.

[8] M. Nishat, Z. M. Dalia \& R. Ahsan Correlation Between Aggregate Crushing Value Of Coarse Aggregate And Compressive Strength Of Concrete, 21-23 December 2016.

[9] Ke-Ru Wu*, Bing Chen, Wu Yao, Dong Zhang Effect of coarse aggregate type on mechanical properties of highperformance concrete, 20 June 2001.

[10] ACI Education Bulletin E1-99 Developed by ACI Committee E-701, Materials for Concrete Construction.

[11] Abdullahi M Effect of aggregate type on Compressive strength of concrete Volume 2, No 3, 2012.

[12] Hassan NS. Effect of grading and types of coarse aggregates on the compressive and flexural strength and unit weight of concrete. Accessed on 10th September, 2014.

[13] Druta, C 2003, "Tensile Strength and Bonding Characteristics of Self-Compacting Concrete", M.Sc. Thesis, Louisiana State.

[14] Aginam, C. H. Chidolue, C. A. And Nwakire, C. Investigating the Effects of Coarse Aggregate Types on the Compressive Strength of Concrete, 2013.

[15] Balamurali Arumugam, SSRG International Journal of Civil Engineering (SSRG-IJCE) "Effect of Specific Gravity on Aggregate Varies the Weight of Concrete Cube" issue 3 August 2014.

[16] Xudong chen, wanshan huang \& jikai zhou, effects of moisture content on compressive and spilt tensile strength of concrete, 8 November 2012.

[17] Mark Alexander and Sidney Mindess aggregate in concrete First published 2005 by Taylor \& Francis.

[18] British Standards (BS). 2009. Testing Aggregates-Methods for Determination of Aggregate Impact Value (AIV), BS 812-112. 